Estudos de Psicologia 2003, 8(3), 421-430

\title{
A Psicologia no novo contexto mundial
}

\author{
Carla Faria Leitão \\ Ana Maria Nicolaci-da-Costa \\ Pontifícia Universidade Católica do Rio de Janeiro
}

\begin{abstract}
Resumo
Profundas alterações no mundo contemporâneo criaram um novo contexto de produção científica, caracterizado pela desconstrução de antigas teorias e pela construção de uma nova rede de conhecimentos. Neste artigo, analisamos algumas teorias recentemente desenvolvidas nas ciências sociais e na Filosofia que compõem esta rede: as teorias pós-modernas, as teorias da modernização reflexiva e a teoria da Revolução da Tecnologia da Informação. Visamos com isto munir os psicólogos de conhecimentos advindos de outros campos disciplinares que sirvam como ponto de partida para a análise das mudanças subjetivas introduzidas pelo novo cenário mundial. Argumentamos que a Psicologia ainda observa o homem contemporâneo a partir de categorias tradicionais, desconsiderando que transformações sociais profundas geram impactos psicológicos não menos profundos e dificilmente captáveis a partir de antigos referenciais. Concluímos que um conhecimento mais aprofundado das transformações radicais em curso no mundo atual pode ajudar os psicólogos a rever suas antigas certezas a respeito do homem e a aventurar novos olhares sobre os também novos fenômenos humanos.
\end{abstract}

Palavras-chave: transformações sociais; impactos subjetivos; novos conhecimentos psicológicos.

\begin{abstract}
Psychology in the new world context. Profound changes in the contemporary world have created a new context for scientific work, characterised by the deconstruction of old theories and the construction of a new network of knowledge. In this article, we analyse a few theories recently developed in the social sciences and in philosophy that make up this network: post-modernist theories, reflexive modernisation theories and Information Technology Revolution theory. In this way, we aim to provide psychologists with insights produced in other fields of knowledge that can serve as a starting point for the analysis of the subjective changes introduced by the new global scenario. We argue that psychology still observes contemporary man on the basis of traditional categories, ignoring the fact that profound social changes generate similarly profound psychological impacts that are unlikely to be detected through the use of old interpretation frameworks. We conclude that a better understanding of the radical changes our world is undergoing should help psychologists revise old certainties and look at new human phenomena in new ways.
\end{abstract}

Key words: social changes; subjective impacts; new psychological knowledge.

\section{Um novo contexto de produção científica: situando a Psicologia}

$\mathrm{A}$ s recentes e radicais alterações do cenário mundial vêm gerando impactos profundos na produção científica contemporânea. Desde a década de 1990, profissionais de diferentes áreas do conhecimento tentam dar sentido a um mundo que, no cotidiano, apresenta-se como caótico. Em conseqüência disto, transformam antigas certezas em dúvidas e desconstroem os sólidos edifícios teóricos de seus campos disciplinares. Grande parte da comunidade acadêmica encontra-se em intensa efervescência intelectual, aguçando seu espírito investigativo e sua criatividade para tecer uma nova rede conceitual que explique a nova realidade mundial.

Nas ciências sociais (notadamente na Sociologia) e na Filosofia, já é possível visualizar alguns efeitos desse novo contexto intelectual. Recentemente, em boa parte dos trabalhos dessas disciplinas, antigas referências teóricas foram abandonadas e novos conhecimentos foram construídos para compreender o mundo globalizado e seus laços de coesão social. 
Observamos, contudo, que o mesmo parece ainda não ocorrer (ao menos com a mesma intensidade) no campo psicológico. Grande parte dos trabalhos da Psicologia continua a utilizar exclusivamente teorias tradicionais para interpretar os impactos psicológicos gerados pelo novo contexto social. Com muita freqüência, os psicólogos analisam novos sentimentos, comportamentos e conflitos humanos como diferentes manifestações de velhas e conhecidas tendências, deixando de captar aquilo que de novo emerge na configuração psicológica do homem contemporâneo ${ }^{1}$.

Este tipo de análise deixa de levar em conta, no entanto, que momentos de profundas transformações sociais geram mudanças de cunho psicológico não menos profundas. Foi isso, por exemplo, o que aconteceu quando, no século XIX, um novo contexto social - construído na Revolução Industrial - introduziu novas formas de pensar, de sentir e de existir para os homens, mulheres e crianças daquela época. Parece ser isso o que está ocorrendo novamente nos dias atuais, quando complexas transformações sociais colocam nossos contemporâneos diante de novas e desconhecidas experiências de vida ${ }^{2}$.

Torna-se, portanto, fundamental que os psicólogos conheçam com maior profundidade as transformações sociais em curso para que sejam capazes de compreender os impactos dessas transformações no plano psicológico. Este é o objetivo de nosso artigo. Por meio da análise de três correntes teóricas da atualidade, pretendemos munir os profissionais da Psicologia de conhecimentos sobre o novo contexto mundial que os incentivem a construir novas categorias para a análise das também novas experiências humanas no mundo atual.

\section{Três correntes teóricas contemporâneas}

Três critérios nortearam a escolha das correntes teóricas que utilizamos para compreender o contexto social no qual as novas questões subjetivas se desenrolam. Em primeiro lugar, essas correntes deveriam fornecer visões amplas daquilo que está acontecendo no mundo atual e nas principais esferas da atividade humana ${ }^{3}$. Em segundo, deveriam discutir o papel fundamental das tecnologias digitais no novo cenário mundial. Finalmente, deveriam abordar questões relacionadas à produção de conhecimentos científicos na contemporaneidade. Três correntes teóricas mostraram-se, então, particularmente interessantes para o nosso objetivo. São elas: as teorias pós-modernas, as teorias da modernização reflexiva e a teoria da Revolução da Tecnologia da Informação.

\section{Teorias pós-modernas}

Originadas no campo da arte e da literatura na década de 1960 , as teorias pós-modernas se difundiram no meio acadêmico somente em 1979, com a publicação da obra $A$ condição pós-moderna, de Jean-François Lyotard. A partir daí, o Pós-modernismo consolidou-se no campo acadêmico, caracterizando-se pela polêmica e pela heterogeneidade. A maioria de suas obras faz uma análise ampla das principais questões que norteiam a vida no mundo atual.
Pelo alto grau de abrangência que apresentam, essas obras resistem a classificações e análises simplistas. Parecenos ser possível, contudo, detectar uma organização das teorias pós-modernas em torno de duas posições principais. A primeira refere-se à ênfase dada à discussão das condições contemporâneas de produção de conhecimento, tendo Lyotard e, mais recentemente, o filósofo Gianni Vattimo como seus representantes mais significativos. Já a segunda dá maior destaque às condições de produção da ordem capitalista contemporânea. Seus principais representantes são autores que sofreram fortes influências das teorias marxistas: David Harvey, Fredric Jameson, Terry Eagleton, Zygmunt Bauman, Richard Sennett e Perry Anderson.

No que se segue, apresentamos, a partir da obra de alguns de seus representantes, essas duas posições pós-modernas. Discutimos as posições epistemológicas de Lyotard e Vattimo e as análises de Jameson, Harvey e Bauman a respeito do capitalismo contemporâneo.

Lyotard e Vattimo: ênfase nas condições de produção de conhecimento. Lyotard (1979), como precursor do Pósmodernismo no campo acadêmico, fornece uma visão panorâmica da Pós-modernidade, comparando as condições de produção científica modernas e pós-modernas.

Segundo esse autor, a Modernidade foi um período histórico no qual, embora o mundo fosse percebido de modo complexo, essas percepções eram organizadas através de sistemas teóricos totalizadores. Por meio desses sistemas chamados por ele de "grandes relatos" -, buscava-se a previsibilidade dos fenômenos, a objetividade e o progresso científicos.

Diferentemente do que aconteceu na Modernidade, Lyotard afirma que vivemos em um período histórico no qual o mundo é percebido como fragmentado, complexo e imprevisível. Na Pós-modernidade não é mais possível descrever o mundo através de discursos científicos unificados em uma meta-linguagem universal. As visões de mundo modernas foram drasticamente desconstruídas e, atualmente, o conhecimento pós-moderno é composto de “pequenos relatos”, ou seja, de narrativas múltiplas sobre um mundo também múltiplo.

Para Lyotard, as transformações na produção contemporânea de conhecimento devem ser entendidas a partir da utilização maciça das tecnologias da informática. O acesso fácil e rápido à informação dissolveu o "grande discurso científico” da Modernidade, rompendo também “a trama enciclopédica na qual cada ciência devia encontrar seu lugar” (Lyotard, 1979, p. 71).

Mais recentemente, Vattimo (1985, 1998a e 1998b) dá continuidade à discussão epistemológica iniciada por Lyotard. Tal como o último, enfatiza a necessidade de desconstruir o modelo moderno de ciência universal, considerando o conhecimento pós-moderno um conjunto de pequenos relatos sobre o mundo. Vattimo, no entanto, aprofunda as discussões a respeito da desconstrução dos grandes relatos científicos, criticando algumas posições teóricas contemporâneas - por ele chamadas de "nostálgicas" - que se reapropriam de conceitos construídos na Modernidade para interpretar as 
atuais transformações mundiais. De sua ótica, os conceitos modernos, além de ineficazes para a análise do que ocorre na Pós-modernidade, refletem uma tentativa inócua de restabelecer a tranqüilidade e a ordem que a ciência moderna propiciava.

Para Vattimo, a dificuldade de lidar com a ruptura e de apreender as características próprias do viver contemporâneo cria, com freqüência, uma visão de que todos os fenômenos atuais são negativos e destruidores de tudo que tínhamos de positivo no mundo. Os nostálgicos encaram a Pósmodernidade como um processo de desumanização de nossa sociedade. Estaríamos vivendo o “inferno da negação do humano” (Vattimo, 1985, p. 18). Essa negatividade impede, no entanto, que uma nova ordem - diferente, mas não menos humana do que a da Modernidade - seja percebida.

De modo análogo ao de Lyotard, Vattimo (1985 e 1998b) também considera as tecnologias da informação a base para o rompimento com a produção moderna de conhecimento. Conforme Vattimo (1985), “a contemporaneidade é a época em que, enquanto, com o aperfeiçoamento dos instrumentos de coleta e transmissão de informação, seria possível realizar uma 'história universal', precisamente essa história se tornou impossível” (p. 11).

Vattimo argumenta, contudo, que as tecnologias digitais são freqüentemente consideradas um instrumento de destruição da humanidade, em vez de um fator de ruptura dos modos tradicionais de interpretação do mundo. Dessa ótica nostálgica, as novas tecnologias da informação afastariam os homens de um relacionamento genuíno e automatizariam suas ações, sendo as vilãs de um cenário pós-moderno desumanizante.

Ainda segundo Vattimo (1998a e 1998b), a análise, sem nostalgias, da penetração das novas tecnologias digitais no cotidiano remete a uma outra relação com o conhecimento, a saber, a de considerar a tecnologia como uma provocação para repensar o mundo. Por um lado, as narrativas universais se enfraquecem, bombardeadas pelo excesso. Por outro, o conhecimento torna-se mais relativizado e afastado de reapropriações teóricas.

Existem, no entanto, outros teóricos da Pós-modernidade que se reapropriam de conceitos modernos para pensar o mundo atual. Fredric Jameson, David Harvey e Zygmunt Bauman são autores que, em oposição a Lyotard e a Vattimo, interpretam os fenômenos pós-modernos através das modernas idéias do marxismo. Passamos, neste ponto, a analisar as obras desses autores.

Jameson, Harvey e Bauman: ênfase nas condições de produção da ordem capitalista. As teorias pós-modernas influenciadas pelo marxismo partem de uma crítica veemente ao que consideram uma "ingenuidade" das concepções de Lyotard sobre a fragmentação do mundo pós-moderno. Do ponto de vista de Harvey (1989), Jameson (1991) e Bauman (1997, 1998), a complexidade e a fragmentação pós-modernas, paradoxalmente, não excluem uma historicidade e uma lógica global de compreensão. Na opinião desse grupo, as teorizações de Lyotard deixam inexplicadas as relações políticas e econômicas do mundo pós-moderno, sendo espantoso o fato de Lyotard ter deixado em segundo plano seu próprio passado marxista, eximindo-se de uma interpretação histórica e temporal da Pós-modernidade (ver Eagleton, 1996 e Anderson, 1998).

Apesar de criticarem sua "ingenuidade”, esses teóricos concordam com as concepções de Lyotard e de Vattimo sobre uma ruptura histórica entre Modernidade e Pós-modernidade. Diferentemente destes, no entanto, Jameson, Harvey e Bauman buscam construir categorias globais para dar sentido à época pós-moderna. Para tanto, enfatizam o modo de produção capitalista como principal categoria de análise, relegando a segundo plano as condições pós-modernas de produção de conhecimento. Nessa visão, a ancoragem da Pós-modernidade é um conjunto de alterações objetivas na ordem econômica do capital.

Jameson (1991) ${ }^{4}$ é - cronologicamente - o primeiro autor a trabalhar nessa direção. Para ele, a Pós-modernidade é uma nova época do capitalismo - a do capitalismo tardio - regida por uma lógica de funcionamento global que perpassa as diferentes esferas da vida humana e dá coesão às mesmas.

Na contemporaneidade, não vigora mais a lógica da produção industrial e a conseqüente divisão entre classes produtoras e trabalhadoras. A esfera econômica se expandiu para todos os níveis do viver humano, inclusive para a esfera cultural. A lógica da Pós-modernidade é aquilo que Jameson chama de lógica cultural do capitalismo tardio. A esfera cultural torna-se coextensiva à economia, não sendo mais possível pensar a cultura como expressão autônoma da organização social. Essa expansão capitalista estruturou nossa sociedade em torno do consumo de bens materiais, de informação e de cultura.

A posição de Jameson frente à tecnologia relaciona-se também à expansão capitalista e à organização da sociedade a partir do consumo. Segundo ele, o desenvolvimento tecnológico, na concepção marxista, é resultado do desenvolvimento do capital e não, como pensam Lyotard e Vattimo, uma instância determinante em si mesma. O desenvolvimento econômico pós-guerra foi o fator que gerou a expansão tecnológica de sistemas aperfeiçoados de automação da produção e da distribuição. Esse quadro, por sua vez, propiciou a intensificação da produção em massa, uma distribuição mais rápida dessa produção e a circulação veloz do capital resultante de suas vendas.

Harvey é outro autor que discute a Pós-modernidade à luz da teoria marxista. Em seu livro Condição pós-moderna, publicado originalmente em 1989, ele reflete, de modo semelhante ao de Jameson, sobre a expansão do capitalismo e sobre a sociedade de consumo. Harvey examina, no entanto, de maneira mais detalhada do que Jameson, o sistema de produção pós-moderno.

Para Harvey, o sistema de produção contemporâneo não é mais, como acontecia na Modernidade, racional, uniforme e padronizado. Na época moderna, cada espaço era destinado à realização de uma tarefa e cada trabalhador especializava-se em uma das etapas produtivas. Ao final do processo, um mesmo produto era produzido em série, de modo rigorosamente uniforme. Já no sistema pós-moderno, o trabalhador 
desempenha tarefas múltiplas e pouco demarcadas. A produção é flexível e voltada para a personalização de bens e serviços. Em um mesmo espaço, são produzidos - em escala industrial - diferentes produtos personalizados. A distribuição desses produtos é mais rápida e a circulação do capital resultante de suas vendas veloz. A lógica pós-moderna de produção é, portanto, flexível, ágil e passível de constantes modificações. Todos esses fatores contribuem, segundo sua análise, para o aumento do consumo a níveis inesgotáveis e para a organização de nossa sociedade em torno desse consumo.

Dentre os autores marxistas pós-modernos, é Bauman $(1997,1998)$ aquele que mais se detém na categoria consumo. Esta é por ele considerada como fator de referência e de organização da sociedade pós-moderna. De sua ótica, todas as sociedades sempre consumiram, mas aquilo que caracteriza a sociedade contemporânea como sociedade de consumo é a ênfase dada a esse consumo. Os membros da sociedade moderna definiam suas redes de sociabilidade em torno da capacidade de produção. Já na Pós-modernidade, a organização social se dá mais pela capacidade e pelo desejo de consumir do que pelo que cada um de seus membros produz.

A tecnologia digital pode ser entendida, em Bauman, tãosomente como mais uma fonte de consumo. A conexão de computadores através da Internet intensificou a possibilidade de consumir e deslocou sua ênfase dos bens materiais para a informação. Grande quantidade de informação é consumida instantaneamente e a custos baixos, independentemente do local onde é gerada ou recebida. Tudo isso cria, de seu ponto de vista, novas formas de exclusão social:

A elogiadíssima “interatividade” do novo veículo é um grande exagero; deveriam antes falar num "meio interativo one-way". Ao contrário do que costumam acreditar os acadêmicos, eles próprios integrantes da nova elite global, a Internet e a Web não são para qualquer um, e é improvável que jamais venham a se abrir para o uso universal (Bauman, 1998, p. 60-1).

O aprofundamento das exclusões sociais no mundo atual em função do desenvolvimento tecnológico vem representar o principal ponto de vista em relação às novas tecnologias da informação presente em sua obra, e também nas de Harvey e Jameson. Em todas elas, a sociedade é estratificada de modo dualista em função do acesso às novas tecnologias digitais. Uma elite detém a informação, e o restante da população é excluído do amplo consumo da mesma.

Tal estratificação social é um dos fatores de discordância entre Bauman, Harvey e Jameson e os filósofos Lyotard e Vattimo. Como foi discutido anteriormente, Lyotard e Vattimo afirmam que o amplo acesso à informação pode gerar visões múltiplas e relativizadas dos fenômenos mundiais, inclusive frente às questões de exclusão social. Já para Harvey, Jameson e Bauman, o acesso à informação é gerador de exclusão e de intolerância nas relações sociais.

A despeito de divergências significativas entre esses dois grupos de teóricos pós-modernos, há em comum entre eles o pressuposto de uma ruptura histórica entre a
Modernidade e a Pós-modernidade. Essa posição, no entanto, está longe de ser unânime dentro do amplo quadro de conhecimentos contemporâneo. Outras correntes teóricas criticam esse pressuposto de ruptura e elaboram outras categorias de análise para a compreensão dos fenômenos da atualidade. A seguir, discutimos uma delas: a das teorias da modernização reflexiva.

\section{Teorias da modernização reflexiva}

As teorias da modernização reflexiva surgiram de uma longa discussão sobre Modernidade versus PósModernidade. Para os sociólogos Ulrich Beck, Anthony Giddens e Scott Lash, não há, como pensam os autores pósmodernos, uma descontinuidade histórica que justifique a demarcação de uma nova época. As transformações sociais em curso configuram tão-somente um outro momento da própria Modernidade.

Ainda em oposição aos teóricos da Pós-modernidade, Beck, Giddens e Lash não consideram que o mundo contemporâneo seja caótico e fragmentado. Para eles, há sempre uma forma de coesão social operante, mesmo que esta se modifique no decorrer do tempo e que não tenha, a princípio, sua lógica reconhecida pelos membros da sociedade.

O livro Modernização reflexiva: política, tradição $e$ estética na ordem social moderna é a obra resultante dessas discussões. Nele, Beck (1995a, 1995b), Giddens (1995) e Lash (1995a, 1995b) investigam as novas formas de coesão social e a unidade básica de organização presente na sociedade atual. Apresentamos, a seguir, os conceitos centrais do trabalho desses três autores.

Beck: a sociedade de risco. Segundo Beck (1999), até a década de 1980, vivíamos um momento da Modernidade no qual o conceito de sociedade era, na maioria das vezes, equivalente ao conceito de Estado. A sociedade era organizada em Estados containers que funcionavam como fonte de referência, de coesão e de proteção para seus membros. Havia, ainda, uma nítida divisão desses membros entre classes trabalhadoras e produtoras, que se organizavam pela lógica da produção industrial.

Notadamente a partir de meados de 1980, um novo momento da Modernidade se instaura sem crises, rupturas ou revoluções. O processo de modernização contínuo e acelerado da sociedade leva-a a romper com algumas de suas principais características. $\mathrm{O}$ aperfeiçoamento dos processos industriais e a globalização enfraquecem os Estados e os levam a se associar e se interpenetrar. A função de referência e de proteção social desempenhada por esses Estados também se enfraquece e, com isto, sentimentos de confusão e de desproteção se instalam nos membros de nossa sociedade contemporânea.

Em paralelo, esta sociedade começa a perceber com maior clareza os efeitos do longo processo de modernização pelo qual passou. Alguns desses efeitos são positivos e cumulativos. Usufruímos, na atualidade, muitos benefícios do desenvolvimento econômico, científico e tecnológico obtido no primeiro momento da Modernidade. Conhecemos melhor o mundo e criamos muitos instrumentos que nos 
auxiliam a nele viver melhor. Por outro lado, sofremos muitos efeitos colaterais resultantes da modernização da sociedade. Passamos a nos dar conta dos riscos gerados por nosso próprio desenvolvimento e sabemos que o controle desses riscos escapa ao poder dos enfraquecidos Estados. Todos os países se encontram simultaneamente, de uma maneira ou de outra, diante de problemas gerados pelo acelerado desenvolvimento mundial. As soluções políticas, econômicas e sociais dependem, antes de tudo, de uma perspectiva de integração global desses problemas por parte de todos os países, envolvendo um sentimento global de humanidade.

O enfraquecimento dos Estados, a desorientação social, a percepção dos riscos gerados pelo desenvolvimento mundial e a emergência de um sentimento de humanidade são, para Beck (1995a, 1995b), os principais fatores que levam a uma nova definição de sociedade e a um novo conceito de modernização neste segundo momento da Modernidade.

Segundo ele, a sociedade contemporânea pode ser mais bem entendida a partir do conceito de sociedade de risco: uma sociedade que passa a perceber - em maior ou menor grau - a necessidade de novas formas de cooperação e de entendimento global para o controle dos riscos gerados por seu desenvolvimento.

O modo de desenvolvimento contemporâneo também se modifica e é definido por Beck como modernização reflexiva. Por modernização reflexiva, Beck compreende o confronto e a interação - e, também, o conflito - dos antigos temas da Modernidade (organização capitalista, produção e consumo, conflitos sociais, etc.) com os novos riscos para a humanidade (destruição do meio-ambiente, catástrofes nucleares, etc.). Não temos uma mera substituição das questões modernas por problemas contemporâneos. Trata-se de "um jogo de duas realidades interagentes” (Beck, 1995b, p. 213): a luta pela distribuição e consumo de bens e serviços e o desafio de lidar com os novos riscos e conseqüências globais. Trata-se, em resumo, da crítica da Modernidade pela própria Modernidade.

Esta crítica comporta, no entanto, uma peculiaridade do ponto de vista do autor. O termo reflexividade corresponde à dimensão não intencional e, portanto, em larga medida, inconsciente de crítica. Beck (1995b) parte da premissa de que a modernização reflexiva é, portanto, um movimento assistemático - científico e cotidiano - para controlar riscos.

O desenvolvimento tecnológico é um dos importantes fatores que geram efeitos e riscos para nossa sociedade. A tecnologia gera efeitos positivos se forem consideradas a acumulação e a circulação de conhecimentos tão fundamentais à vida contemporânea. Todo desenvolvimento tecnológico envolve, no entanto, a dimensão de risco para a humanidade e são esses os aspectos tecnológicos enfatizados por Beck. São destacados os riscos de vida (gerados pelo desenvolvimento da indústria bélica e por seu conseqüente poder de destruição), a destruição ecológica (em função da própria infra-estrutura das indústrias de tecnologia e do aproveitamento de materiais do meio-ambiente pelas mesmas) e, por fim, os riscos de exclusão social que o desenvolvimento das novas tecnologias da informação pode criar.
Giddens: percepção individual dos riscos. Giddens (1995) discute o conceito de sociedade de risco, dando maior ênfase à percepção que cada membro de nossa sociedade tem dos riscos globais e às formas como modificam seus valores e seus laços de coesão social.

De seu ponto de vista, os homens da sociedade contemporânea estão tendo que construir e aprender novos valores, hábitos e tradições em função da nova referência social (a de humanidade). Segundo Giddens (1999), o mundo sempre enfrentou riscos, mas as soluções para os mesmos eram encontradas dentro da bagagem de tradição que recebíamos através da cadeia de gerações. Os atuais efeitos colaterais da modernização são, entretanto, distintos daqueles que outras gerações enfrentaram. Não temos experiências anteriores que nos orientem sobre o que fazer diante deles. Para conviver com isso, nos voltamos para as tradições acumuladas e para a rede de conhecimentos recentemente produzidos, refletindo sobre as mesmas e criticando-as.

O conceito de modernização reflexiva, em Giddens (1995), enfatiza, de forma análoga à de Beck, a crítica dos conhecimentos gerados num primeiro momento da Modernidade com vistas à construção de novas tradições e conhecimentos. Percebe-se, no entanto, uma diferença importante entre as definições desse conceito em Giddens e em Beck. Giddens considera que os homens contemporâneos podem adquirir a capacidade de refletir conscientemente sobre as condições sociais de sua existência e, assim, modificá-las. Nesse sentido, a modernização reflexiva envolve a reflexão sistemática e consciente sobre os conhecimentos científicos e cotidianos. Como foi discutido anteriormente, para Beck, essa reflexão é assistemática e, em grande medida, inconsciente.

A reflexão consciente sobre os conhecimentos, sobre as tradições e sobre os riscos de nossa sociedade é, para Giddens, favorecida pelo desenvolvimento acelerado das novas tecnologias da informação. A conexão do planeta através de uma poderosa rede de comunicação propiciou a circulação rápida de informações sobre riscos presentes nas mais diversas partes do globo, gerando um maior conhecimento dos mesmos por pessoas de todo o planeta. É essa condição tecnológica que o último autor dessa linha, o sociólogo Scott Lash, vai desenvolver em suas contribuições teóricas, como discutimos a seguir.

Lash: tecnologia como base da sociedade de risco. Lash (1995a), como Giddens, considera que a modernização reflexiva envolve um olhar crítico, sistemático e consciente para os conhecimentos modernos. Segundo ele, a base de sustentação que permite que a Modernidade tome, nesse momento, seus próprios conhecimentos como objeto de crítica é a tecnologia digital. Dessa ótica, a reflexividade é sustentada por um entrelaçamento de redes globais e locais de comunicação que disponibilizam os conhecimentos de forma nunca vista. Tanto a comunidade científica como a população leiga têm maior acesso aos conhecimentos produzidos e podem incrementar o raciocínio crítico e a reflexão. Através da rede global de comunicação, os conhecimentos acerca do mundo rompem as grades institucionais às quais se 
circunscreviam e tornam-se objetos de crítica e de reflexão generalizados.

A modernização reflexiva relaciona-se, de seu ponto de vista, à qualificação e ao engajamento dos membros da sociedade nessa rede global de comunicação. $\mathrm{O}$ acesso à rede vem gerando, no entanto, novas exclusões sociais. Conforme Lash (1995b), "o acesso a essas estruturas de informação e comunicação - que são desigualmente distribuídas tanto espacial quanto socialmente - é um fator cada vez mais fundamental na desigualdade de classe, raça e gênero no mundo atual” (p. 253).

Diferentemente de Giddens, Lash revela que, a despeito de discordar da ruptura entre Modernidade e Pósmodernidade, compartilha da crítica social pós-moderna. Para ele, apesar de o conhecimento estar disponível para as elites culturais cada vez mais qualificadas, para a grande maioria da população a crítica e capacitação ainda permanecem distantes.

A seguir, abordamos uma outra teoria que também analisa, embora de modo diferente, a conexão do globo em redes de informação: a da Revolução da Tecnologia da Informação, desenvolvida pelo sociólogo Manuel Castells.

\section{Teoria da Revolução da Tecnologia da Informação}

A obra de Manuel Castells faz parte de um recente campo de teorias no qual o desenvolvimento das novas tecnologias de informação ocupa posição central. O marco desse tipo de raciocínio encontra-se nas idéias precursoras do teórico da comunicação Marshall McLuhan que, já nos anos de 1960, analisava as mudanças sociais criadas pelas tecnologias da mídia televisiva (ver McLuhan, 1962). No início da década de 1980, McLuhan reafirmava sua sensibilidade para as grandes transformações humanas geradas por novas tecnologias. Desta vez, seu olhar se voltava para as tecnologias da informática. Em 1986, sua última obra - The Global Village: transformations in the world life and media in the $21^{\text {st }}$ century - inaugurava um novo campo de estudos dedicado à investigação dos impactos sociais que as novas tecnologias digitais começavam a criar.

A influência de McLuhan gerou frutos em diversas áreas do conhecimento. Na área da mídia, Douglas Rushkoff (1997) é considerado o autor que dá continuidade ao seu pensamento polêmico, analisando, da ótica das crianças, as características da vida digital. Na filosofia, Pierre Lévy $(1995,1998)$ é um dos autores mais significativos, investigando as características de um novo estilo cultural: a cibercultura. Na informática, Philippe Breton (1987) e Nicholas Negroponte (1995) traçam o percurso histórico e cultural das novas tecnologias digitais.

É no campo das ciências sociais, no entanto, que encontramos a mais valiosa contribuição teórica sobre as novas tecnologias da informação: a extensa obra do sociólogo Manuel Castells, publicada em 1999, sobre a Revolução da Tecnologia da Informação. Em seus três volumes - A sociedade em rede, $O$ poder da identidade e Fim de milênio -, Castells sistematiza a história dessas tecnologias, seus conceitos, seus paradigmas e seus impactos sociais. No que se segue, apresentamos alguns dos principais pontos de sua análise.
Castells e a sociedade em rede. Castells (1999), tal como os autores da modernização reflexiva, analisa a sociedade contemporânea a partir de sua organização em uma rede global de informação. Diferentemente desses autores, contudo, pressupõe que estamos em meio a uma revolução histórica e não tão-somente diante de transformações sub-reptícias no interior da Modernidade:

Uma revolução tecnológica concentrada nas tecnologias da informação está remodelando a base material da sociedade em ritmo acelerado. (...) As redes interativas de computadores estão crescendo exponencialmente, criando novas formas e canais de comunicação, moldando a vida e, ao mesmo tempo, sendo moldadas por ela (Castells, 1999, pp. 21-22).

Ao considerar que a sociedade contemporânea passa por uma revolução, Castells aproxima-se do conceito de ruptura dos teóricos da Pós-modernidade. Essa aproximação é, no entanto, limitada. Isso porque ele critica intensamente o uso do conceito de fragmentação pós-moderna, julgando-o uma renúncia à capacidade de entender o mundo e de agir sobre ele.

A compreensão das atuais mudanças mundiais é fornecida, em Castells, pelo paradigma tecnológico. As tecnologias da informação, diferentemente do que ocorre nas duas correntes teóricas descritas anteriormente, são minuciosamente definidas e discutidas, havendo, inclusive, uma análise histórica de seu surgimento e de sua penetração social.

Segundo Castells, as tecnologias da informação definemse basicamente por sua convergência. Provenientes de campos disciplinares distintos, essas tecnologias formam hoje um conjunto integrado de instrumentos com o objetivo de coletar, processar, transmitir e reprogramar informações. As tecnologias que formam esse conjunto são as da eletrônica (circuitos, chips, etc.), da informática (hardware e software), das telecomunicações/ radiodifusão (satélites de comunicação, linhas de transmissão, etc.) e da optoeletrônica (como por exemplo, a fibra ótica) ${ }^{5}$.

Castells argumenta que a análise desse conjunto convergente de tecnologias possibilita uma melhor compreensão da sociedade contemporânea. Para isso, ele expõe seis características do que chama de paradigma tecnológico.

A primeira refere-se ao papel que a informação - no sentido amplo de comunicação de conhecimentos - alcança na sociedade contemporânea. Para Castells, estamos testemunhando um ponto de descontinuidade histórica no qual a informação assume papel central, sendo a própria fonte de produtividade, ou seja, a matéria-prima de nossa sociedade. Passamos de um período em que a informação capacitava a sociedade para a atividade produtiva, para outro em que a atividade produtiva central é a própria transmissão da informação. Até a década de 1970, a informação agia sobre a tecnologia. Transmitiam-se conhecimentos sobre as etapas de transformação de matérias-primas em produto e sobre a utilização de tecnologias no processo produtivo. O recente desenvolvimento tecnológico, no entanto, converteu a 
capacidade de gerar informação em força produtiva direta. A partir de meados da década de 1970, não é a informação que age sobre a tecnologia. É a tecnologia que age sobre a informação.

A segunda característica diz respeito ao grau de penetração das tecnologias digitais. Como a informação é parte integral de toda atividade humana, todas as esferas da existência individual e coletiva são influenciadas diretamente pelas novas tecnologias da informação. Devido a essa extensiva penetração, participamos da formação de uma nova economia - nova, mas ainda capitalista - e de uma nova cultura. A tecnologia é fator constitutivo da nova organização econômica e social, sem que, no entanto, a isso se atribua um caráter determinista. Para Castells, a tecnologia molda a organização da sociedade e, retroativamente, é moldada pelo uso que a sociedade faz dela. Os membros de uma sociedade transformam-se ao adotar novas ferramentas tecnológicas mas, ao adotá-las, eles também as adaptam criativamente.

A terceira característica descrita por Castells é a lógica de redes presente no conjunto das relações sociais. A estrutura descentralizada - mas integrada - que molda as novas tecnologias da informação fornece uma morfologia que melhor se adapta à crescente complexidade das relações do mundo contemporâneo. A lógica de redes possibilita que visualizemos e estruturemos as novas mudanças da sociedade que, a princípio, são percebidas como não-estruturadas.

Em relação estreita com a lógica de redes, Castells define a quarta característica do paradigma tecnológico: a flexibilidade. A rede estrutura o não-estruturado, preservando sua flexibilidade. As organizações, instituições e relações sociais são, na contemporaneidade, processos reversíveis e dinâmicos que revertem regras continuamente sem destruir sua estrutura.

Já a quinta refere-se à acima citada convergência de tecnologias em uma rede altamente integrada e inseparável, o que gera uma profunda interdependência de fatores na constituição de uma nova forma de organização social.

Por fim, a última característica do paradigma tecnológico é a da transformação das categorias de análise do mundo:

A partir da observação dessas mudanças extraordinárias em nossas máquinas e conhecimentos, está havendo uma transformação tecnológica mais profunda: a das categorias segundo as quais pensamos todos os processos. (...) O paradigma da tecnologia da informação não evolui para seu fechamento como um sistema, mas rumo à abertura como uma rede de acessos múltiplos (Castells, 1999, pp. 80-81).

Para Castells, os conhecimentos contemporâneos estão, em grande parte, baseados em novas categorias de análise que captam adequadamente os novos fenômenos. Esses conhecimentos são, além disso, abertos e complexos. Não temos, na atualidade, modelos conceituais fechados em sistemas definidos. Segundo ele, temos redes conceituais abertas, nas quais os conceitos têm “acessos múltiplos”. Diferentes redes se encontram através de nós conceituais comuns, e também se afastam através de outros nós divergentes.
Essas seis características do paradigma tecnológico levam Castells a propor o conceito de rede como categoria central para analisar a sociedade contemporânea. Ele argumenta que a morfologia da rede constitui nossa organização social, definindo os diferentes domínios da atividade e da experiência humanas. Reproduzimos aqui um trecho dessa argumentação que, apesar de um pouco extenso, dá a dimensão da complexidade de seu raciocínio:

Rede é um conjunto de nós interconectados. Nó é o ponto no qual uma curva se entrecorta. Concretamente, o que um nó é depende do tipo de redes concretas de que falamos. São mercados de bolsas de valores e suas centrais de serviços auxiliares avançados na rede dos fluxos globais. (...) São campos de coca e de papoula, laboratórios clandestinos, pistas de aterrissagem secretas, gangues de rua e instituições financeiras para lavagem de dinheiro, na rede de tráfico que invade as economias, sociedades e Estados do mundo inteiro. (...) A topologia definida por redes determina que a distância (ou intensidade e freqüência da interação) entre dois pontos (ou posições sociais) é menor (ou mais freqüente e mais intensa), se ambos os pontos forem nós de uma rede do que se não pertencerem à mesma rede. (...) A inclusão/exclusão em redes e a arquitetura das relações entre redes, possibilitadas por tecnologias da informação que operam à velocidade da luz, configuram os processos e funções predominantes em nossas sociedades (Castells, 1999, p. 498).

No conceito de rede está presente a noção de interdependência entre fenômenos e organizações sociais. A sociedade em rede inclui, também, a dimensão do consumo destacada pelos pós-modernos. As tecnologias da informação reestruturam as relações de poder, criando um emaranhado de fios no qual a informação é disputada como mercadoria e como fonte de dominação. As relações de inclusão/exclusão social são, no entanto, tratadas de forma mais complexa do que na visão dos autores pós-modernos. Para estes, vale lembrar, enquanto uma elite se conecta à rede de consumo global, o restante da população permanece excluída. Embora, para Castells, a inclusão ou a exclusão em uma rede também sejam critérios de hierarquização social, o problema não é tão simples como o dualismo inclusão/exclusão pode fazer supor. Há que considerar também as relações entre as inúmeras redes sociais existentes. Podemos ser excluídos de uma rede e incluídos em outras. Podemos assumir, simultaneamente, diferentes posições de inclusão e exclusão em diferentes redes. É a arquitetura de relações entre diferentes redes que estrutura as complexas formas de dominação social vigentes nos dias de hoje.

\section{A construção de novas redes conceituais: um desafio para a Psicologia}

Por meio da análise que fizemos acima, foi possível acompanhar o esforço que autores representantes das três correntes teóricas examinadas neste artigo empreenderam para romper com os sólidos sistemas conceituais de suas disciplinas. Esses autores abriram mão da segurança que os 
conhecimentos tradicionais ofereciam e, com ousadia e criatividade, passaram a elaborar novas categorias para interpretar um novo contexto social.

Este tipo de raciocínio - que privilegia a ruptura com antigas formas de conhecer a realidade - resgata o caráter provisório, historicamente datado e socialmente determinado de todo conhecimento científico. Enquanto vivíamos um período de longa estabilidade social, criamos a ilusão de que nossos conhecimentos sobre o mundo eram definitivos. Julgávamos que as categorias de que dispúnhamos eram suficientes e eficazes para analisar e compreender tudo o que acontecia (ou viria a acontecer) no mundo. Atualmente quando radicais mudanças na ordem social revolucionam as diferentes esferas da atividade humana -, essa ilusão cai por terra. Somos intimados a relembrar que um conjunto de conhecimentos criados para compreender uma determinada ordem social é inadequado para a análise de outras.

Parece-nos, contudo, que a Psicologia continua resistente a este tipo de reflexão crítica. Como já mencionamos, grande parte dos psicólogos continua presa a antigas categorias e não opera nenhuma ruptura com o corpo de conhecimentos de nossa disciplina.

O contraste de duas posturas tão distintas frente à atual produção de conhecimentos causa impacto e estranhamento. Temos, de um lado, a postura de continuidade teórica da Psicologia e, de outro, a de ruptura que caracteriza as correntes teóricas aqui apresentadas.

Esse estranhamento pode, contudo, servir como um convite para que nós, na qualidade de psicólogos, comecemos a repensar criticamente a postura continuísta que muitos de nós estamos adotando. Tal procedimento pode, por exemplo, nos levar a reconhecer que o atual corpo teórico da Psicologia foi construído para compreender a existência humana em uma ordem social que hoje já não existe mais (a respeito da construção dessa antiga ordem, ver Figueiredo, 1992). Pode, ainda, nos ajudar a enxergar que a Psicologia, tal como a conhecemos hoje, não oferece categorias que possibilitem a identificação das mudanças psicológicas introduzidas pela nova ordem mundial.

Ocorre, porém, que o reconhecimento da atual inadequação do corpo de conhecimentos psicológicos não vem se revelando uma tarefa fácil. Um dos obstáculos envolvidos parece ser o medo de que a Psicologia possa vir a desaparecer caso não haja ferramentas adequadas para interpretar as transformações psicológicas em curso. Neste caso, entretanto, deixa-se de registrar que uma das principais funções da Psicologia é a de identificar, descrever, interpretar e compreender as novas organizações subjetivas que são geradas em diferentes contextos históricos e sociais, sejam estes já conhecidos ou totalmente novos (a este respeito, ver Nicolaci-da-Costa, 2002b).

Durante muito tempo, dado que os diferentes contextos do mundo em que vivíamos eram estáveis e facilmente reconhecíveis, não havia maiores dificuldades em identificar e interpretar, do ponto de vista da Psicologia, as inúmeras e sutis facetas da existência humana. No tempo presente, no entanto, as profundas mudanças sociais pelas quais estamos passando nos levam a desconhecer as principais características do mundo atual e, conseqüentemente, as transformações psicológicas geradas por este novo mundo. Diante destas transformações, a função da Psicologia contemporânea passa a ser a de identificar, descrever e analisar as novas organizações subjetivas geradas em um novo (e pouco conhecido) contexto histórico e social.

Parece-nos, portanto, que o desaparecimento da Psicologia como campo da ciência está longe de se colocar como questão. O que parece estar em jogo é o desafio de reformular os conhecimentos psicológicos para que os mesmos acompanhem as transformações em curso na atualidade. Para tanto, é imperativo que, em um primeiro momento, os psicólogos travem contato com a produção teórica de outras disciplinas, a fim de conhecer as principais características do novo contexto mundial e seus também novos laços de coesão social.

Consideramos que as correntes teóricas discutidas ao longo deste artigo podem ser particularmente úteis como ponto de partida para este instigante desafio. Como foi visto, teorias recentemente construídas na Sociologia e na Filosofia já fornecem categorias de análise que tornam a sociedade atual, senão menos assustadora, pelo menos mais conhecida. Estas teorias tornam claras algumas das principais referências sociais que vêm servindo de âncoras para novos processos de construção subjetiva. Apontam, por exemplo, para o surgimento de um mundo globalizado, no qual a referência de humanidade começa a ganhar força ao mesmo tempo em que novos e desconhecidos riscos rondam a existência humana. Apontam, ainda, para as novas modalidades de consumo que organizam a sociedade contemporânea. Apontam, finalmente, para o revolucionário papel que as novas tecnologias da informação vêm exercendo nas diferentes esferas da atividade humana, criando novas formas de lidar com diferentes tipos de informação, bem como novas formas de relacionamento entre nações, grupos e pessoas.

Tudo isso se reflete no plano da existência individual, transformando radicalmente as formas de o sujeito contemporâneo agir, pensar, sentir e se relacionar consigo e com os outros. Conhecendo um pouco melhor as âncoras sociais que, recentemente, começam a servir de referência para a existência humana, talvez possamos, na qualidade de psicólogos, aventurar novos olhares sobre nossos contemporâneos e, assim, a tecer uma nova rede de conhecimentos psicológicos mais compatíveis com a atualidade. Se, enquanto psicólogos, não estivermos atentos a estas mudanças, dificilmente conseguiremos rever nossas antigas certezas e participar com mais segurança e criatividade do novo contexto contemporâneo de produção científica.

\section{Agradecimentos}

O presente trabalho faz parte da Tese de Doutorado Os impactos subjetivos da Internet: reflexões teóricas e clínicas, da primeira autora, sob a orientação da segunda, no Programa de Pós-graduação em Psicologia Clínica da PUC-Rio. As 
autoras agradecem o apoio das bolsas do CNPq e da FAPERJ concedidas à primeira autora.

\section{Referências}

Anderson, P. (1998). As origens da pós-modernidade. Rio de Janeiro: Jorge Zahar.

Bauman, Z. (1997). O mal-estar da pós-modernidade. Rio de Janeiro: Jorge Zahar.

Bauman, Z. (1998). Globalização: as conseqüências humanas. Rio de Janeiro: Jorge Zahar.

Beck, U. (1995a). A reinvenção da política: rumo a uma teoria da modernização reflexiva. In U. Beck, A. Giddens \& S. Lash (Orgs.), Modernização reflexiva: política, tradição e estética na ordem social moderna (pp. 1171). São Paulo: Editora da Universidade Estadual Paulista.

Beck, U. (1995b). Autodissolução e auto-risco da sociedade industrial: o que isso significa? In U. Beck, A. Giddens \& S. Lash (Orgs.), Modernização reflexiva: política, tradição e estética na ordem social moderna (pp. 207218). São Paulo: Editora da Universidade Estadual Paulista.

Beck, U. (1999, 23 de maio). Sociedade de risco. Folha de São Paulo (Mais!), pp. 5.

Berger, P., \& Luckman, T. (1967). A construção social da realidade. Petrópolis: Vozes.

Breton, P. (1987). História da Informática. São Paulo: Editora da Universidade Estadual Paulista.

Canclini, N. G. (1995). Consumidores e cidadãos: conflitos multiculturais da globalização. Rio de Janeiro: Editora da UFRJ.

Castells, M. (1999). A sociedade em rede. São Paulo: Paz e Terra.

Durkheim, E. (1982). O suicídio: um estudo sociológico. Rio de Janeiro: Zahar (obra originalmente publicada em 1897).

Eagleton, T. (1996). As ilusões do pós-modernismo. Rio de Janeiro: Jorge Zahar.

Elias, N. (1987). A sociedade dos indivíduos. Rio de Janeiro: Jorge Zahar.

Figueiredo, L. C. (1992). A invenção do psicológico: quatro séculos de subjetivação (1500-1900). São Paulo: Escuta.

Gerschman, S., \& Vianna, M. L. (Orgs.). (1997). A miragem da pósmodernidade: democracia e políticas sociais no contexto da globalização. Rio de Janeiro: Editora FioCruz.

Giddens, A. (1995). A vida em uma sociedade pós-industrial. In U. Beck, A. Giddens \& S. Lash (Orgs.), Modernização reflexiva: política, tradição e estética na ordem social moderna (pp. 73-133). São Paulo: Editora da Universidade Estadual Paulista.

Giddens, A. (1999, 23 de maio). Giddens rejeita brasilização. Folha de São Paulo (Mais!), pp. 5-6.

Greenfield, D. (1999). Psychological characteristics of compulsive Internet use: a preliminary analysis. Acessado em 19 de fevereiro de 2001, de http://www.virtual-addiction.com.

Harvey, D. (1989). Condição pós-moderna. São Paulo: Loyola.

Jameson, F. (1991). Pós-modernismo: a lógica cultural do capitalismo tardio. São Paulo: Ática.

Lash, S. (1995a). A reflexividade e seus duplos: estrutura, estética, comunidade. In U. Beck, U., A. Giddens \& S. Lash (Orgs.), Modernização reflexiva: política, tradição e estética na ordem social moderna (pp. 135-206). São Paulo: Editora da Universidade Estadual Paulista.
Lash, S. (1995b). Sistemas especialistas ou interpretação situada? Cultura e instituições no capitalismo desorganizado. In U. Beck, U., A. Giddens \& S. Lash (Orgs.), Modernização reflexiva: política, tradição e estética na ordem social moderna (pp. 235-253). São Paulo: Editora da Universidade Estadual Paulista.

Lévy, P. (1995). O que é virtual. São Paulo: Editora 34.

Lévy, P. (1998). The universal without totality, essence of cyberculture. In E. R. Larreta (Org.), Media and social perception (pp. 199-207). Rio de Janeiro: UNESCO, ISSC, EDUCAM.

Lyotard, J. F. (1979). A condição pós-moderna. Rio de Janeiro: José Olympio.

McLuhan, M. (1962). A galáxia de Gutenberg: a formação do homem tipográfico. São Paulo: Companhia Editora Nacional.

McLuhan, M., \& Powers, B. (1986). The global village: transformations in world life and media in $21^{\text {st }}$ century. Nova York: Oxford University Press.

Negroponte, N. (1995). Vida digital. São Paulo: Companhia das Letras.

Nicolaci-da-Costa A. M. (1987). Sujeito e cotidiano: um estudo da dimensão psicológica do social. Rio de Janeiro: Campus.

Nicolaci-da-Costa A. M. (1998). Na malha da rede: os impactos íntimos da Internet. Rio de Janeiro: Campus.

Nicolaci-da-Costa A. M. (2000). A tecnologia da intimidade. In Anais do III Workshop de Fatores Humanos em Sistemas Computacionais (pp. 155177). Porto Alegre: Impa.

Nicolaci-da-Costa A. M. (2002a). Internet: a negatividade do discurso da mídia versus a positividade da experiência pessoal. A qual dar crédito? Estudos de Psicologia (Natal), 7, 25-36.

Nicolaci-da-Costa A. M. (2002b). Revoluções tecnológicas e transformações subjetivas. Psicologia: Teoria e Pesquisa, 2, 193-202.

Nisbet, R. A. (1966). The sociological tradition. Nova York: Basic Books.

Ribeiro, G. L. (2000). Cultura e política no mundo contemporâneo. Brasília: Editora da UnB.

Ribeiro Coutinho, A. M. (1985). Pressupostos da noção de subjetividade. In S. A. Figueira (Org.), Cultura da Psicanálise (pp. 62-93). São Paulo: Brasiliense.

Romão-Dias, D. (2001). Nossa plural realidade: um estudo sobre a subjetividade na era da Internet. Dissertação de mestrado não-publicada, Pontifícia Universidade Católica do Rio de Janeiro, Rio de Janeiro.

Rushkoff, D. (1997). Um jogo chamado futuro: como a cultura dos garotos pode nos ensinar a sobreviver na era do caos. Rio de Janeiro: Revan.

Sarlo, B. (1994). Cenas da vida pós-moderna. Rio de Janeiro: Editora UFRJ.

Simmel, G. (1987). A metrópole e a vida mental. In O. G. Velho (Org.), O fenômeno urbano (pp. 11-25). Rio de Janeiro: Guanabara (obra originalmente publicada em 1902-3).

Vattimo, G. (1985). O fim da modernidade: niilismo e hermenêutica na cultura pós-moderna. São Paulo: Martins Fontes.

Vattimo, G. (1998a). Estamos perdendo a razão? In Le nouvel observateur Café Philo: as grandes indagações da filosofia (pp. 60-63). Rio de Janeiro: Zahar.

Vattimo, G. (1998b). The Mass-overman. In E. R. Larreta (Org.), Media and social perception (pp. 57-65). Rio de Janeiro: UNESCO, ISSC, EDUCAM.

Young, K. (1998). Caught in the net: how to recognize the signs of the Internet addiction and winning strategy for recovery. Nova York: Wiley.

Zaremba, R. (2001). Escrevendo (ou seria 'teclando'?!) o homem do século XXI. Dissertação de mestrado não-publicada, Pontifícia Universidade Católica do Rio de Janeiro, Rio de Janeiro. 


\section{Notas}

1. As recentes pesquisas psicológicas sobre o uso cotidiano da Internet são um bom exemplo da utilização de antigas referências teóricas para a análise de novos comportamentos. Algumas dessas pesquisas comparam a utilização intensiva da Rede a uma outra categoria usada tradicionalmente no campo psicológico: a do vício a drogas ou ao jogo (ver, por exemplo, Young, 1998 e Greenfield, 1999). Em contrapartida, já é possível encontrar outras pesquisas que analisam os impactos subjetivos das novas tecnologias digitais a partir de novas categorias de pensamento, evitando, assim, enquadrar novas experiências humanas em antigos quadros patológicos (a esse respeito, ver Nicolaci-da-Costa, 1998, 2000, 2002a e 2002b; Romão-Dias, 2001 e Zaremba, 2001).

2. Um conjunto consistente e heterogêneo de trabalhos - advindos tanto da Psicologia quanto da Sociologia dedica-se à discussão do papel do social na construção do psicológico. Alguns deles adotam um foco amplo e abrangente (ver, por exemplo, Berger \& Luckman, 1967; Elias, 1987; Ribeiro-Coutinho, 1985 e Nicolaci-daCosta, 1987). Já outros se concentram na análise da configuração psicológica gerada pela Revolução Industrial (ver Nisbet, 1966; Simmel, 1902-3/1987 e Durkheim, 1897/1982). Mais recentemente, alguns trabalhos traçam um paralelo entre os impactos psicológicos gerados pela Revolução Industrial e os recentes impactos introduzidos pela realidade contemporânea (Castells, 1999 e Nicolaci-da-Costa, 1998, por exemplo).

3. Tendo em vista que o presente artigo busca fornecer ao leitor uma visão panorâmica das transformações em curso no mundo contemporâneo, os trabalhos aqui examinados abordam aspectos genéricos da nova realidade mundial, deixando de contemplar as especificidades do cenário brasileiro. Já existe, no entanto, um conjunto expressivo de trabalhos que abordam questões relativas ao contexto latino-americano em geral e ao brasileiro em particular. A análise destas questões foge, no entanto, aos objetivos deste artigo. A este respeito, ver, por exemplo, Sarlo (1994), Canclini (1995), Gerschman \& Vianna (1997) e Ribeiro (2000).

4. A obra de Jameson foi publicada na íntegra, originalmente, em 1991. O conteúdo do famoso texto "A lógica cultural do capitalismo tardio" foi, no entanto, divulgado pela primeira vez em uma conferência em 1982 (ver Anderson, 1998).

5. Diferentemente de outros autores (Breton, 1987 e Lévy, 1990, por exemplo), Castells considera a engenharia genética uma tecnologia da informação. De seu ponto de vista, a genética, de modo análogo ao da informática, também manipula informações. A diferença entre esses dois campos está no tipo de informação que manipulam. Enquanto a engenharia genética atua sobre a matéria viva, a informática age sobre conhecimentos. Esta definição foge, no entanto, aos objetivos de nosso artigo.

Carla Faria Leitão é psicóloga graduada pela Universidade do Estado do Rio de Janeiro, especialista em Saúde Mental pelo Instituto de Psiquiatria da Universidade Federal do Rio de Janeiro e Mestre em Psicologia Clínica pela Pontifícia Universidade Católica do Rio de Janeiro. Atualmente, finaliza o Curso de Doutorado, também pela PUC-Rio, como bolsista nota 10 da FAPERJ.

Ana Maria Nicolaci-da-Costa é Master of Arts em Psicologia pela New School for Social Research, em Nova York, EUA, e Ph.D., também em Psicologia, pela University of London, Reino Unido.

Endereço para correspondência: Departamento de Psicologia - PUC-Rio; Rua Marquês de São Vicente, 225 - Gávea; 22543-900 - Rio de Janeiro, RJ. E-mails: [CFL] carlaleitao@uol.com.br [AMNC] anicol@psi.pucrio.br 